удК 339.5.053

А. Ф. Шуплецов

Байкальский государственный университет, г. Иркутск, Российская Федераиия

Н. В. Светник

Байкальский государственный университет, г. Иркутск, Российская Федерация

\title{
ВЛИЯНИЕ НА АКТИВНОСТЬ ПРОМЫШЛЕННОЙ ПОЛИТИКИ И ПРЕДПРИНИМАТЕЛЬСТВА В ВОСТОЧНЫХ РЕГИОНАХ РОССИИ БАЛАНСА ВНЕШНЕЙ ТОРГОВЛИ РОССИИ И ЯПОНИИ
}

АНнотАция. В условиях частичной переориентации внимания России на восток становится все более актуальным вопрос о сотрудничестве Москвы и Токио. Камнем преткновения для полномасштабного развития отношений японская сторона видит «проблему северных территорий» или принадлежности Курильских островов. Взаимное беспокойство вызывает отсутствие мирного договора между странами. Тем не менее, японские инвесторы занимают лидирующую позицию среди стран Азии по объему финансовых вливаний в экономику РФ. Анализ торгового баланса Японии говорит о том, что она успешно поддерживает статус высокотехнологичной страны и испытывает недостаток минерального топлива и химической продукции в связи с географическим положением. Переработка отечественных минеральных и химических ресурсов позволила бы России частично занять эту нишу. Текущий год можно считать новым периодом укрепления российско-японских отношений. И уже сейчас реализуется и согласовывается ряд совместных проектов с японскими инвесторами. Улучшение российско-японских отношений окажет положительное воздействие и в рамках стратегии развития Сибири и Дальнего Востока.

кЛЮчЕВЫЕ СЛОВА. Россия; Япония; АТР; экспорт; импорт; торговый баланс; внешняя торговля; экономическое развитие; российско-японские отношения; Дальний Восток; Сибирь; инвестиции; инвестиционные проекты.

ИНФОРМАЦИЯ О СТАТЬЕ. Дата поступления 5 ноября 2016 г.; дата принятия к печати 23 ноября 2016 г.; дата онлайн-размещения 30 ноября 2016 г.

\author{
A. F. Shupletsov \\ Baikal State University, \\ Irkutsk, Russian Federation \\ N. V. Svetnik \\ Baikal State University, \\ Irkutsk, Russian Federation
}

\section{IMPACT OF FOREIGN TRADE BALANCE BETWEEN RUSSIA AND JAPAN ON PERFORMANCE OF INDUSTRIAL POLICY AND BUSINESS IN RUSSIA'S EASTERN REGIONS}

\begin{abstract}
In terms of partial reorientation of Russia's attention on the East, the issue of cooperation of Moscow and Tokyo is becoming ever more topical. The problem of «the Northern Territories» and ownership of the Kuril Islands is considered by the Japanese party as a stumbling point for full-scale development of relations. The mutual anxiety is caused by absence of the Treaty of Peace between the countries. Nevertheless, the Japanese investors take a leading position among Asian countries in the amount of financial injections into the RF economy. Analysis of Japan's trade balance testifies the fact that it successfully maintains the status of a highly technological country and suffers a shortage of mineral fuel and chemical products
\end{abstract}

\section{Baikal Research Journal}


in the context of its geographical position. Processing domestic mineral and chemical resources would allow Russia to partially carve out the niche. Even now a number of joint projects with Japanese investors is being implemented and agreed upon. Improving Russo-Japanese relations will also make a positive effect in terms of the development strategy for Siberia and the Far East.

KEYWORDS. Russia; Japan; A/P ex JPN; export; import; trade balance; foreign trade; economic development; Russo-Japanese relations; the Far East; Siberia; investments; investment projects.

ARTICLE INFO. Received November 5, 2016; accepted November 23, 2016; available online November 30, 2016.

В последнее время в работах, рассматривающих варианты расширения экономических связей России на восток и переориентацию на сотрудничество со странами Азиатско-Тихоокеанского региона (АТP), в большинстве случаев ключевым партнером выступает Китай [1-3 и др.]. Постепенно Пекин занял лидирующие позиции в ведущих региональных организациях [4], тем не менее, условия ведения бизнеса в стране находятся на более низком уровне, чем в Южной Корее и Японии [5].

Сегодня, несмотря на расхождение интересов в отношении Курильских островов, отсутствие мирного договора, Москва и Токио ищут точки соприкосновения в экономике, энергетике, промышленности. В последнее время эта тенденция только усиливается. В конце 2014 г. Япония вышла на первое место в Азии по инвестициям в российскую экономику [6]. В структуре экспорта РФ она занимает 7-е место (4,22\% от общего объема или 14,490 млрд дол. США), импорта 6 -е место $\left(3,24 \%\right.$ от общего объема или 6,813 млрд дол. США) ${ }^{1}$.

В текущей ситуации санкционных ограничений проанализируем торговый баланс страны восходящего солнца в целом и по товарным группам. Попытаемся оценить направления для расширения сотрудничества России и Японии.

Согласно статистике министерства финансов Японии за 2015 г. $^{2}$, среди крупных торговых партнеров, отдельно выделяемых в отчетности, Россия находилась на 22 -м месте с $0,82 \%$ от общего объема экспорта $(617,659$ млрд йен - порядка 5,808 млрд дол. США ${ }^{3}$. Тройка самых крупных стран-импортеров японских товаров: США - 20,13 \% (143,161 млрд дол. США), Китай $-17,49 \%$ $(124,342$ млрд дол. США) и Южная Корея $-10,56 \%$ (50,087 млрд дол. США) соответственно. В целом экспорт ориентирован на Азию - 53,33\% от общего количества.

Следует отметить, что по сравнению с 2014 г. японо-российский экспорт уменьшился на значительные 36,4 \% в основном за счет сокращения поставок автомобилей. Японцы обеспокоены этой тенденцией и отмечают, что промышленная структура нашей страны быстро меняется. «Бывшее при смерти российское машиностроение начало просыпаться от долгого сна», - пишет Нобуо Сугавара [7].

Российские товары в Японии находятся на 12 -м месте с $2,43 \%$ от общего объема импорта (1 904,711 млрд йен - порядка 17,910 млрд дол. США). Больше всего экспортировалось товаров из Китая $-24,78$ \% (182,694 млрд дол. США), США 10,28 \% (75,788 млрд дол. США) и Австралии - 5,37 \% (39,588 млрд дол. США) соответственно. В совокупности наибольший поток экспорта идет в Японию из Азии $-48,92 \%$.

Ведущие позиции мирового экспорта и импорта Японии в распределении по товарным группам представлены в таблице.

\footnotetext{
${ }^{1}$ Составлено по данным Федеральной таможенной службы. URL : http://stat.customs.ru.

${ }^{2}$ Составлено по данным Japan Customs. URL: http://www.customs.go.jp.

${ }^{3}$ Здесь и далее по курсу йены к доллару США: JPY/USD $=0.01, \mathrm{USD} / \mathrm{JPY}=106.74$.
}

\section{Baikal Research Journal}


Укрупненная структура внешней торговли Японии в 2015 г.

\begin{tabular}{|c|c|c|c|}
\hline $\begin{array}{c}\text { Англоязычное } \\
\text { наименование } \\
\text { товарной группы } \\
\text { (код) }\end{array}$ & Перевод & $\begin{array}{c}\text { Соответствие } \\
\text { ТН ВЭД РФ }\end{array}$ & $\begin{array}{l}\text { Доля от общего } \\
\text { объема экспор- } \\
\text { та/импорта, \% }\end{array}$ \\
\hline \multicolumn{4}{|c|}{ Экспорт } \\
\hline $\begin{array}{l}\text { Transport } \\
\text { equipment (705) }\end{array}$ & $\begin{array}{l}\text { Транспортные средства } \\
\text { и оборудование }\end{array}$ & \multirow{3}{*}{$\begin{array}{l}\text { Разделы XVI, XVII, XVIII (ча- } \\
\text { стично), XX (подгруппа 9405) }\end{array}$} & 24 \\
\hline Machinery (7) & Машины и оборудование & & 19,1 \\
\hline $\begin{array}{l}\text { Electrical } \\
\text { machinery (703) }\end{array}$ & $\begin{array}{l}\text { Электрические машины } \\
\text { и оборудование }\end{array}$ & & 17,6 \\
\hline $\begin{array}{l}\text { Manufactured } \\
\text { goods (6) }\end{array}$ & $\begin{array}{l}\text { Товары промышленного } \\
\text { назначения / промыш- } \\
\text { ленные товары }\end{array}$ & $\begin{array}{l}\text { Разделы VII (исключая груп- } \\
\text { пу 39), VIII, IX (исключая } \\
\text { подгруппу 4402), X, XI }\end{array}$ & 12,2 \\
\hline Chemicals (5) & Химическая продукция & $\begin{array}{l}\text { V (исключая группу 27), VI } \\
\text { (исключая группу 37); VII (ис- } \\
\text { ключая группу 40); XIII, XV }\end{array}$ & 10,3 \\
\hline \multicolumn{4}{|c|}{ Илипорт } \\
\hline Mineral fuels (3) & Минеральное топливо & $\begin{array}{l}\text { Разделы V (группа 27), } \\
\text { IX (подгруппа 4402) }\end{array}$ & 23,2 \\
\hline $\begin{array}{l}\text { Electrical } \\
\text { machinery (703) }\end{array}$ & $\begin{array}{l}\text { Электрические машины } \\
\text { и оборудование }\end{array}$ & $\begin{array}{l}\text { Разделы XVI, XVII, XVIII (ча- } \\
\text { стично); XX (подгруппа 9405) }\end{array}$ & 15,3 \\
\hline Others (8) & Другое & $\begin{array}{l}\text { Раздел ХХ. Разные промыш- } \\
\text { ленные товары }\end{array}$ & 14,5 \\
\hline Chemicals (5) & Химическая продукция & $\begin{array}{l}\text { Разделы V (исключая группу } \\
27), \text { VI (исключая группу 37); } \\
\text { VII (исключая группу 40); } \\
\text { XIII, XV }\end{array}$ & 9,9 \\
\hline
\end{tabular}

Составлено по данным информационного портала «Таможня для всех». URL: http://www. customs.go.jp, http://www.tks.ru.

Объем японского экспорта и его укрупненная структура, в которой преобладают транспортные средства, машины и электрические машины, говорит о том, что Япония успешно поддерживает статус высокотехнологичной страны и подтверждает верность высказывания: «до настоящего времени в инновационной сфере азиатские страны продолжают зависеть от японской экономики и технологической политики ее корпораций» [8].

Обобщенная структура японского импорта подчеркивает недостаток минерального топлива и химической продукции в связи с географическим положением. Размер доли электрических машин, вероятно, связан с тем, что, продавая технологии изготовления подобного оборудования в страны Азии, Япония покупает у них готовый продукт с меньшими издержками, чем при производстве внутри страны. Наладив переработку отечественных минеральных и химических ресурсов, у РФ была бы возможность частично занять эту нишу в экспорте товаров в Японию.

Обратим внимание, что из России Япония импортирует в основном сырье (raw materials) - 71,9\% от общего объема российского импорта, в то время как экспортирует транспортные средства и оборудование (transport equipment) и машины и оборудование (machinery) - 56,9 \% и 15,8 \% от общего объема экспорта в РФ соответственно. При этом высказывание премьер-министра Японии Абэ Синдзо о том, что отношения между экономиками наших стран не являются конкурентными и прекрасно дополняют друг друга, приобретает новый, не самый приятный для России смысл.

Несмотря на этот контекст, 2016 г. можно считать новым периодом укрепления российско-японских отношений. Сначала 6 мая на саммите в Сочи состоялась

\section{Baikal Research Journal}


встреча лидеров двух стран. Со стороны Японии был вынесен набор предложений из восьми пунктов, к которому Синдзо Абэ частично обращался в своем выступлении 3 сентября на Восточном экономическом форуме 2016. Предложения японской стороны касаются следующего ряда вопросов:

- увеличения продолжительности жизни россиян за счет сотрудничества в медицинской сфере и строительства больниц японского образца. Абэ подчеркнул, что наша страна одна из немногих, где наблюдает прирост населения;

- повседневных городских проблем населения, вызванных с загруженностью автомобильного движения, утилизацией отходов, надежность коммунальных сетей, экологии и др., в решении которых важную роль может сыграть опыт и технологии Японии;

- расширения контактов, кооперации российско-японских предприятий с ярким акцентом на малый и средний бизнес и венчурные компании;

- совместного освоения и эксплуатации нефтегазовых и других энергетических ресурсов, увеличения стадий переработки сырой нефти и, следовательно, расширения номенклатуры;

- увеличения производительности и диверсификации предприятий РФ, используя, в том числе, такой метод, как «кайдзэн» - таких улучшений, когда они идут снизу вверх, от самых младших сотрудников к управленцам и инженерам. Эта эффективная система, помогающая постепенно снижать количество бракованных изделий, впервые появилась именно в Японии и постепенно успешно распространилась, к сожалению, как не преминул заметить премьер-министр, практически не затронув России;

- интенсивного развития промышленности Дальнего Востока и создания экспортной базы для всех стран АТР;

- атомно-энергетического сотрудничества, ИТ-технологий и др. высоких технологий для консолидации интеллектуальных возможностей обеих стран;

- укрепления связей между обычными гражданами Японии и России за счет научных и студенческих обменов, спортивных мероприятий, туризма и т. д.

Во Владивостоке Абэ внес предложение о ежегодных встречах на площадке во Владивостоке для проверки претворения в жизнь всех восьми пунктов. А в декабре должен состояться визит российского президента в Японию.

В. В. Путин с большим вниманием отнесся к этому предложению, подчеркивая, что Япония сосед и важный партнер РФ. Наша страна поддержала идею развития по всем направлениям, но с определенной долей скепсиса. Причина в сильном влиянии Вашингтона на Токио, по причине которого многие договоренности могут утратить силу. Тем не менее, лидер «Новой партии Дайти», Судзуки Мунэо, считает, что у Японии нет необходимости занимать одинаковую с США и Европой позицию, она может иметь собственные суждения [9].

Помимо причин, перечисленных японской стороной, у России есть особый резон стремиться сотрудничеству на Дальнем Востоке - Китай. Протяженная граница и приграничное население в пропорции порядка 1 к 15 не в пользу россиян, вызывает обоснованное беспокойство правительства и потребность в передовых японских технологиях, так как промышленного, сырьевого и экономического потенциала недостаточно для эффективного развития территорий [10].

Необходимость стабилизации российской экономики создает основу для усиления процессов привлечения иностранного капитала [11]. Уже сейчас реализуется и согласовывается ряд совместных проектов с японскими инвесторами. Так, в Красноярском крае в результате соглашения между филиалом ООО «Комацу СНГ» и Дивногорским техникумом лесных технологий откроется учебный центр по подготовке специалистов лесозаготовки высокого класса. В Дальневосточном

\section{Baikal Research Journal}


федеральном округе Mitsui ведет переговоры с ПАО «РАО ЭС Востока» о совместном строительстве ветряных электростанций; обсуждается проект прокладки подводного кабеля от о. Сахалин до о. Хоккайдо; также в рамках проекта «Сахалин-2» планируется расширение завода по производству СПГ с привлечением корпорации Mitsubishi. В Приморском крае в с. Суражевка на площади 5 га JFE Engineering Corporation совместно с ФГУП «Дальневосточное» намереваются построить теплицы; также японские бизнесмены заинтересованы инвестировать в экспортную инфраструктуру края.

Иркутскую область с Японией связывают отношения с марта 1967 г., когда Иркутск стал побратимом г. Канадзава. С тех пор ведутся разносторонние обмены студентами, одна из центральных улиц переименована в ул. Канадзавы, в 2002 г. открыт Японский информационный центр - единственный от Урала до Хабаровского края. Позднее, столицы Восточной Сибири побратимами стали еще три города области: Братск и Нагано, Шелехов и Номи, Железногорск-Илимский и Саката.

В конце 2015 г. запущен проект по разработке нефтяного месторождения Ичединское, участниками которого являются ООО «ИНК» (Иркутская нефтяная компания) совместно с японскими партнерами: ITOCHU Corporation, INPEX Corporation и Японской национальной корпорацией по нефти, газу и металлам (JOGMEC). Как отмечает Е. Дементьева - это первый опыт инвестирования японских компаний в освоение нефтяных месторождений Восточной Сибири [12]. При помощи японских инвестиций в 1999 г. было построено одно из ведущих медицинских учреждений Иркутска и области - ОГАУЗ «Иркутский областной клинический консультативно-диагностический центр» (ИДЦ). Также на протяжении многих лет из Иркутской области экспортируются в Японию топливно-энергетические и лесные ресурсы. Сотрудничество продолжает развиваться.

Еще больше проектов по формированию нового Дальнего Востока находятся на стадии разработке и будут рассмотрены сторонами на российско-японском саммите, который пройдет уже на территории Синдзо Абэ в декабре. Улучшение российско-японских отношений также выгодно и для нашей страны, вписывается в стратегию развития Сибири и Дальнего Востока.

Но следует не упускать из внимания тот факт, что каждая страна, стремящаяся к сотрудничеству, преследует свои цели, следовательно, необходим тщательный отбор предложений.

\section{Список использованной литературы}

1. Бейдина Т. Е. Региональная политика в Забайкальском крае: монгольский и китайский факторы / Т. Е. Бейдина, А. В. Новикова // Вестник Забайкальского государственного университета. - 2016. - № 3. - С. $42-49$.

2. Зимовец А. В. О проблемах и перспективах переориентации экономики России с Запада на Восток // А. В. Зимовец // Вестник Таганрогского института управления и экономики. - 2014. - № 1 (19). - С. 33-36.

3. Нехорошков В. П. Особенности межрегионального внешнеэкономического сотрудничества приграничных субъектов России и Китая / В. П. Нехорошков, А. В. Новикова // Научные проблемы транспорта Сибири и Дальнего Востока. - 2014. - № 4. - С. 18-21.

4. Лузянин С. Г. «Возвышение» Китая как фактор мировой политики [Электронный peсурс] / С. Г. Лузянин // Известия Иркутской государственной экономической академии (Байкальский государственный университет экономики и права). -2015 . - № 5. - Peжим доступа: http://eizvestia.isea.ru/reader/article.aspx?id=19427.

5. Санина Л. В. Россия и страны Восточной Азии в международных рейтингах оценки предпринимательского климата / Л. В. Санина // Развитие российско-китайских отношений: новая международная реальность : материалы 2-й Междунар. науч.-практ. конф.,

\section{Baikal Research Journal}

электронный научный журнал Байкальского государственного университета 
посвящ. 70-летию Победы во Второй мировой войне. Иркутск, 21-22 сент. 2015 г. : в 2 ч. / под ред. А. П. Суходолова, Т. Г. Озерниковой. - Иркутск : Изд-во Байкал. гос. ун-та, 2016. - Ч. 1. - С. 218-229.

6. Мануков С. Территориальный спор, энергетический союз [Электронный ресурс] / С. Мануков // Expert Online. - 2016. - 13 нояб. - Режим доступа: http://expert. $\mathrm{ru} / 2016 / 04 / 16 /$ abe/.

7. Сугавара Н. Объем российско-японской торговли сокращается - очарование Японией растет [Электронный ресурс] / H. Сугавара // ИноСМИ.RU. - 2016. - 19 авг. - Peжим доступа: http://inosmi.ru/social/20160819/237582773.html.

8. Кохно П. Тенденции развития высокотехнологичной промышленности / П. Кохно, С. Чеботарев, Т. Глыбина // Общество и экономика. - 2015. - № 4. - С. 44-63.

9. Судзуки Мунэо. К улучшению японско-российских отношений: Япония, больше самостоятельности! [Электронный ресурс] : интервью с лидером «Новой партии Дайти» Судзуки Мунэо / записал Д. Харано // Nippon Communications Foundation. - 2015. 7 aпр. - Режим доступа: http://www.nippon.com/ru/in-depth/a04004/.

10. Шуплецов А. Ф. Роль ресурсного потенциала и предпринимательских структур муниципальных образований Иркутской области в эффективном развитии региональной экономики [Электронный ресурс] / А. Ф. Шуплецов, Е. С. Нечаева // Baikal Research Journal. - 2015. — T. 6, № 4. - DOI: 10.17150/2411-6262.2015.6(4).9.

11. Бойко Т. С. Иностранный капитал как фактор развития экономики региона [Электронный ресурс] / Т. С. Бойко, Н. С. Фролова // Известия Иркутской государственной экономической академии (Байкальский государственный университет экономики и права). 2014. - № 6. - Режим доступа: http://eizvestia.isea.ru/reader/article.aspx?id=19805.

12. Дементьева Е. Миллионные вливания [Электронный ресурс] / Е. Дементьева // Российская газета. - 2015. - 17 дек. - Режим доступа: https://rg.ru/2015/12/17/regsibfo/neft.html.

\section{References}

1. Beidina T. E., Novikova A. V. Regional policy in Zabaikalye Territory: Mongolian and Chinese factors. Vestnik Zabaikal'skogo gosudarstvennogo universiteta = Zabaikalye State University Journal, 2016, no. 3, pp. 42-49. (In Russian).

2. Zimovets A. V. On problems and prospects of Russia's economy reorientation from West to East. Vestnik Taganrogskogo instituta upravleniya $i$ ekonomiki = Bulletin of Taganrog Institute of management and Economics, 2014, no. 1 (19), pp. 33-36. (In Russian).

3. Nekhoroshkov V. P., Novikova A. V. Peculiarities of interregional economic cooperation between border regions of Russia and China. Nauchnye problemy transporta Sibiri $i$ Dal'nego Vostoka = Scientific Problems of Transport in Siberia and the Far East, 2014, no. 4, pp. 18-21. (In Russian).

4. Luzyanin S. G. "Rise» of China as a factor of the world policy. Izvestiya Irkutskoi go sudarstvennoi ekonomicheskoi akademii (Baykalskii gosudarstvennyi universitet ekonomiki $i$ prava) $=$ Bulletin of Irkutsk State Economics Academy (Baikal State University of Economics and Law), 2015, no. 5.

5. Sanina L. V. Russia and East-Asian countries in international business climate assessment ratings. In Sukhodolov A. P., Ozernikova T. G. (eds). Razvitie rossiisko-kitaiskikh otnoshenii: novaya mezhdunarodnaya real'nost'. Materialy 2-i Mezhdunarodnoi nauchno-prakticheskoi konferentsii, posvyashchennoi 70-letiyu Pobedy vo Vtoroi mirovoi voine. Irkutsk, 21-22 sentyabrya $2015 \mathrm{~g}$. [Development of Russo-Chinese relations: a new international reality. Materials of 2-nd International Science and Practice Conference devoted to 70-th Anniversary of the Victory in the Second World War. Irkutsk, September 21-22, 2015]. Irkutsk, Baikal State University Publ., 2016, pr. 1, pp. 218-229. (In Russian).

6. Manukov S. Territorial dispute, energy power alliance. Expert Online, 2016, November 13. Available at: http://expert.ru/2016/04/16/abe/.(In Russian).

7. Sugavara N. The volume of Russo-Japanese trade is increasing. InoSMI.RU, 2016, August 19. Available at: http://inosmi.ru/social/20160819/237582773.html. (In Russian).

8. Kokhno P., Chebotarev C., Glybina T. Trends of developing highly technological industry. Obshchestvo $i$ ekonomika = Science and Economy, 2015, no. 4, pp. 44-63. (In Russian).

\section{Baikal Research Journal}

электронный научный журнал Байкальского государственного университета 
9. Sudzuki Muneo. On improving Russo-Japanese relations: Japan, more self-sufficiency!: Interview with the leader of «New Party Daity» Sudzuki Muneo. Nippon Communications Foundation, 2015, April 7. Available at: http://www.nippon.com/ru/in-depth/a04004/. (In Russian).

10. Shupletsov A. F., Nechayeva E. S. R Role of resource potential and business structures of municipal entities of Irkutsk Oblast in effective development of regional economy. Baikal Research Journal, 2015, vol. 6, no. 4. DOI: 10.17150/2411-6262.2015.6(4).9. (In Russian).

11. Boiko T. S., Frolova N. S. Foreign capital as a factor of regional economic development. Izvestiya Irkutskoi gosudarstvennoi ekonomicheskoi akademii (Baykalskii gosudarstvennyi universitet ekonomiki $i$ prava) $=$ Bulletin of Irkutsk State Economics Academy (Baikal State University of Economics and Law), 2014, no. 6. Available at: http://eizvestia.isea.ru/ reader/article.aspx?id $=19805$. (In Russian).

12. Dementyeva E. Million-strong financial injections. Rossiiskaya Gazeta, 2015, December 17. Available at: https://rg.ru/2015/12/17/reg-sibfo/neft.html. (In Russian).

\section{Информация об авторах}

Шуплецов Александр Федорович - экономических наук, профессор, заведующий кафедрой экономики предприятия и предпринимательской деятельности, Байкальский государственный университет, 664003, г. Иркутск, ул. Ленина, 11, e-mail: ssa@isea.ru.

Светник Наталия Васильевна - аспирант, кафедра экономики предприятия и предпринимательской деятельности, Байкальский государственный университет, 664003, г. Иркутск, ул. Ленина, 11, e-mail: patjob@yandex.ru.

\section{Authors}

Aleksandr V. Shupletsov - Doctor habil. (Economics), Professor, Head of Chair of Enterprise Economy and Entrepreneurship Activity, Baikal State University, 11 Lenin St., 664003, Irkutsk, Russian Federation; e-mail: ssa@isea.ru.

Natalya V. Svetnik - PhD Student, Chair of Enterprise Economy and Entrepreneurship Activity, Baikal State University, 11 Lenin St., 664003, Irkutsk, Russian Federation; e-mail: patjob@yandex.ru.

\section{Библиографическое описание статьи}

Шуплецов А. Ф. Влияние на активность промышленной политики и предпринимательства в восточных регионах России баланса внешней торговли России и Японии / А. Ф. Шуплецов, Н. В. Светник // Baikal Research Journal. — 2016. — T. 7, № 6. - DOI: 10.17150/2411-6262.2016.7(6).9.

\section{Reference to article}

Shupletsov A. F., Svetnik N. V. Impact of foreign trade balance between Russia and Japan on performance of industrial policy and business in Russia's eastern regions. Baikal Research Journal, 2016, vol. 7, no. 6. DOI: 10.17150/2411-6262.2016.7(6).9. (In Russian).

\section{Baikal Research Journal}

